\title{
ATRIBUTOS QUÍMICOS E FÍSICOS DE SOLO CULTIVADO COM OLERÁCEAS EM MICROBACIA HIDROGRÁFICA, APÓS DESASTRE AMBIENTAL
}

\author{
Celeste Queiroz Rossi( ${ }^{(1)}$, Marcos Gervasio Pereira ${ }^{(2) *}$, Adriana Maria de Aquino ${ }^{(3)}$, Sandra \\ Santana de Lima ${ }^{(1)}$ e Ricardo Luis Louro Berbara ${ }^{(2)}$
}

\footnotetext{
(1) Universidade Federal Rural do Rio de Janeiro, Departamento de Solos, Programa de Pós-graduação em Ciência do Solo, Seropédica, Rio de Janeiro, Brasil.

(2) Universidade Federal Rural do Rio de Janeiro, Departamento de Solos, Seropédica, Rio de Janeiro, Brasil.

(3) Empresa Brasileira de Pesquisa Agropecuária, Embrapa Agrobiologia, Seropédica, Rio de Janeiro, Brasil.

* Autor correspondente.

E-mail: gervasio@ufrrj.br
}

\section{RESUMO}

A matéria orgânica do solo é uma importante fonte primária de nutrientes às plantas e influencia a infiltração, retenção de água, suscetibilidade à erosão e agregação do solo. No entanto, esse processo está condicionado à qualidade e quantidade da matéria orgânica aportada. $O$ objetivo deste trabalho foi avaliar a influência do desastre ambiental causado pela chuva em áreas de produção de oleráceas na região Serrana do Rio de Janeiro. Foram selecionadas as seguintes áreas: A1: sem impacto (testemunha); A2: soterramento total e cultivo de aveia + ervilhaca; A3: transbordamento do rio e cultivo de milheto + girassol; A4: transbordamento do rio e grande deposição de areia com cultivo de aveia-preta; A5: transbordamento do rio com grande deposição de areia e sem cultivo; e A6: transbordamento do rio em pequena escala e sem cultivo. As propriedades edáficas analisadas foram: textura; densidade do solo (Ds); densidade de partículas (Dp); diâmetro médio ponderado (DMP) e diâmetro médio geométrico (DMG) de agregados estáveis em água; $\mathrm{pH}\left(\mathrm{H}_{2} \mathrm{O}\right), \mathrm{Al}^{3+}, \mathrm{Ca}^{2+}+\mathrm{Mg}^{2+}$, $\mathrm{Na}^{+}, \mathrm{H}+\mathrm{Al}, \mathrm{K}, \mathrm{P}$ e carbono orgânico total (COT); e frações granulométricas e químicas da matéria orgânica. Os maiores valores de DMP e DMG foram observados nas áreas A3 e A6, que seguem a mesma tendência dos maiores teores de argila. Os teores de COT e suas frações químicas e físicas apresentaram diferenças em relação à testemunha com os menores valores verificados nas áreas que foram submetidas ao impacto pelo transbordamento do rio e grande deposição de areia. As áreas que foram impactadas pelo soterramento com predomínio 
da fração argila apresentaram valores semelhantes ou superiores aos da testemunha. As variáveis foram selecionadas e avaliadas por meio da análise de componentes principais, que evidenciou distinção entre as áreas estudadas, com separação entre elas associada à textura do solo e densidade de partículas.

Palavras-chave: diâmetro médio ponderado, impacto ambiental, soterramento, matéria orgânica do solo.

\title{
ABSTRACT: CHEMICAL AND PHYSICAL PROPERTIES OF SOIL UNDER VEGETABLE CROPPING IN WATERSHEDS, AFTER ENVIRONMENTAL DISASTER
}

\begin{abstract}
Soil organic matter is an important primary source of nutrients for plants and influences infiltration, water retention, susceptibility to erosion, and soil aggregation. However, this process is conditioned on the quality and quantity of organic matter supplied. The objective of this study was to evaluate the influence of the environmental disaster caused by rain in areas of horticulture production in the mountainous region of Rio de Janeiro. The following areas were selected: A1- no impact (control); A2 - totally covered by landslide and cultivation of oats + vetch; A3 - river overflow and cultivation of millet + sunflower; A4 - river overflow and extensive deposition of sand and growing of black oats; A5 - river overflow with extensive deposition of sand and no cultivation; and A6 - river overflow on a small scale and no cultivation. The soil properties analyzed were texture; bulk density (BD); particle density (Pd); mean weight diameter (MWD) and geometric mean diameter (GMD) of water-stable aggregates; $\mathrm{pH}\left(\mathrm{H}_{2} \mathrm{O}\right), \mathrm{Al}^{3+}, \mathrm{Ca}^{2+}+\mathrm{Mg}^{2+}, \mathrm{Na}^{+}, \mathrm{H}+\mathrm{Al}, \mathrm{K}, \mathrm{P}$, and total organic carbon (TOC); and particle size and chemical organic matter fractions. The highest values of the DMG and DMP were observed in areas $A 6$ and A3, which also have the highest clay contents. The TOC content and its chemical and physical fractions showed differences compared to the control, with the lowest values observed in areas that underwent the impact of river overflow and extensive sand deposition, since the areas that were affected by landslide with predominance of the clay fraction showed values similar or superior to reference values. Principal component analysis clearly showed a distinction among the areas studied, and this distinction is clearly associated with soil texture and particle density.
\end{abstract}

Keywords: weighted average diameter, environmental impact, landslide, soil organic matter.

\section{INTRODUÇÃO}

O município de Nova Friburgo, localizado na região Serrana fluminense, é reconhecido como pólo econômico regional pela importante produção e distribuição de oleráceas para a região metropolitana do Rio de Janeiro. Em janeiro de 2011, as vulnerabilidades a mbientais e agrícolas da região foram potencializadas com as fortes chuvas, quando, de acordo com a Secretaria de Agricultura e Pecuária do Estado do Rio de Janeiro (SEAPEC-RJ, 2011), a região recebeu $182,8 \mathrm{~mm}$ de chuva em $2 \mathrm{~h}$, provocando sérios danos em $60 \%$ do município. Foram registradas perdas nas áreas agrícolas causadas por erosões, deslizamento de encostas e transbordamentos dos cursos d'agua; mais de 60 \% das áreas atingidas eram cultivadas com olericultura. Nesses ambientes poucos são os estudos que avaliam as modificações nos atributos do solo após a ocorrência dos desastres ambientais.

Para recuperar a capacidade produtiva dos solos das áreas mais prejudicadas, os agricultores passaram a manejar o solo com elevadas doses de adubos químicos e cama de aviário na tentativa de restabelecer a fertilidade. Contudo, a produtividade das culturas não atingiu níveis desejados em muitas propriedades. Nesse sentido, preconizou-se a utilização da matéria orgânica a partir da adubação verde, por ser de grande importância e contribuir em diversos processos químicos, físicos e biológicos no solo (Christensen, 2000; Carter, 2001; Mielniczuk, 2008). A matéria orgânica do solo (MOS) é fonte primária de nutrientes às plantas, influencia a infiltração e retenção de água e a suscetibilidade à erosão (Gregorich et al., 1994), atuando ainda sobre a ciclagem de nutrientes e agregação do solo. No entanto, esse processo está condicionado à qualidade e quantidade da matéria orgânica aportada. A adubação verde é uma prática que contribui para o aumento dos teores de matéria orgânica ao solo e pode atuar no restabelecimento da capacidade produtiva das áreas impactadas.

Objetivou-se avaliar os atributos químicos e físicos e a dinâmica da matéria orgânica do solo nas áreas de produção após impacto ambiental, partindo da hipótese de que manejos dessa natureza aumentam as qualidades química e física do solo. 


\section{MATERIAL E MÉTODOS}

A região Serrana fluminense caracteriza-se por relevos montanhosos, onde podem ser observados solos com baixo grau de desenvolvimento pedogenético, como Cambissolos, associados a solos com maior grau de pedogênese como Argissolos. O clima é caracterizado como subtropical úmido, do tipo $\mathrm{Cfa}$, de acordo com a classificação climática de Köppen-Geiger. Essa região é naturalmente vulnerável a deslizamentos, e os poucos remanescentes da Mata Atlântica desempenham papel muito importante na captação e distribuição da água da chuva nas bacias hidrográficas.

Foram avaliadas seis áreas de produção de oleráceas $(0,20 \mathrm{ha})$ localizadas na microbacia Barracão dos Mendes, Nova Friburgo, RJ, concentrada na comunidade Fazenda Rio Grande (Figura 1, Quadro 1).

A coleta de solo foi realizada em maio de 2013, 28 meses após o desastre ambiental ocorrido em janeiro de 2011, em áreas onde aconteceu uma série de eventos como deslizamentos e soterramentos. Os solos das áreas A1, A2 e A3 foram classificados anteriormente ao desastre como Argissolos Amarelos; e os das áreas A4, A5 e A6, como Gleissolos Háplicos, segundo o Sistema Brasileiro de Classificação do Solo (Santos et al., 2013a). Em cada área, foram abertas três trincheiras e coletadas amostras com estrutura preservada e não preservada em três profundidades 0,00-0,05; 0,05-0,10; e 0,10-0,20 m. As amostras foram secas ao ar, destorroadas e passadas por peneira de $2 \mathrm{~mm}$.
Para a caracterização química, foram realizadas as análises: $\mathrm{pH}$ em água, complexo sortivo $\left(\mathrm{Al}^{3+}\right.$, $\mathrm{Ca}^{2+}, \mathrm{Mg}^{2+}, \mathrm{Na}^{+}, \mathrm{H}+\mathrm{Al}, \mathrm{P}$ e K), segundo Embrapa (1997); a partir desses, foram calculados os valores S, T e V. O carbono orgânico total (COT) foi determinado por oxidação quente com dicromato de potássio $\left(0,167 \mathrm{~mol} \mathrm{~L}^{-1}\right)$ e titulação com sulfato ferroso amoniacal $\left(0,20 \mathrm{~mol} \mathrm{~L}^{-1}\right)$, de acordo com Yeomans e Bremner (1988). O estoque de C foi calculado pelo método da massa equivalente, sendo a correção dos estoques de C do solo efetuada, considerando as diferenças nas massas de solo de cada camada (Sisti et al., 2004), com o objetivo de eliminar a ocorrência de diferenças provenientes da densidade do solo.

O fracionamento granulométrico da matéria orgânica (MO) foi feito de acordo com Cambardella e Elliott (1992). Para a extração e o fracionamento químico da matéria orgânica do solo (MOS), utilizou-se a técnica de solubilidade diferencial (Swift, 1996), conforme adaptação de Benites et al. (2003), obtendo-se o $\mathrm{C}$ orgânico nas frações ácidos fúlvicos (C-FAF), os ácidos húmicos (C-FAH) e a humina (C-HUM).

A determinação dos atributos físicos densidade do solo (Ds), densidade de partículas (Dp), estabilidade dos agregados (DMP e DMG) e granulometria foi realizada a partir dos métodos descritos em Embrapa (1997).

A análise dos dados foi feita considerando o delineamento inteiramente casualizado, com seis tratamentos e seis repetições, para cada variável avaliada, até a profundidade de 0,20 m. Os testes de Lilliefors e Cochran e Barttlet foram utilizados para análise da normalidade e homogeneidade das

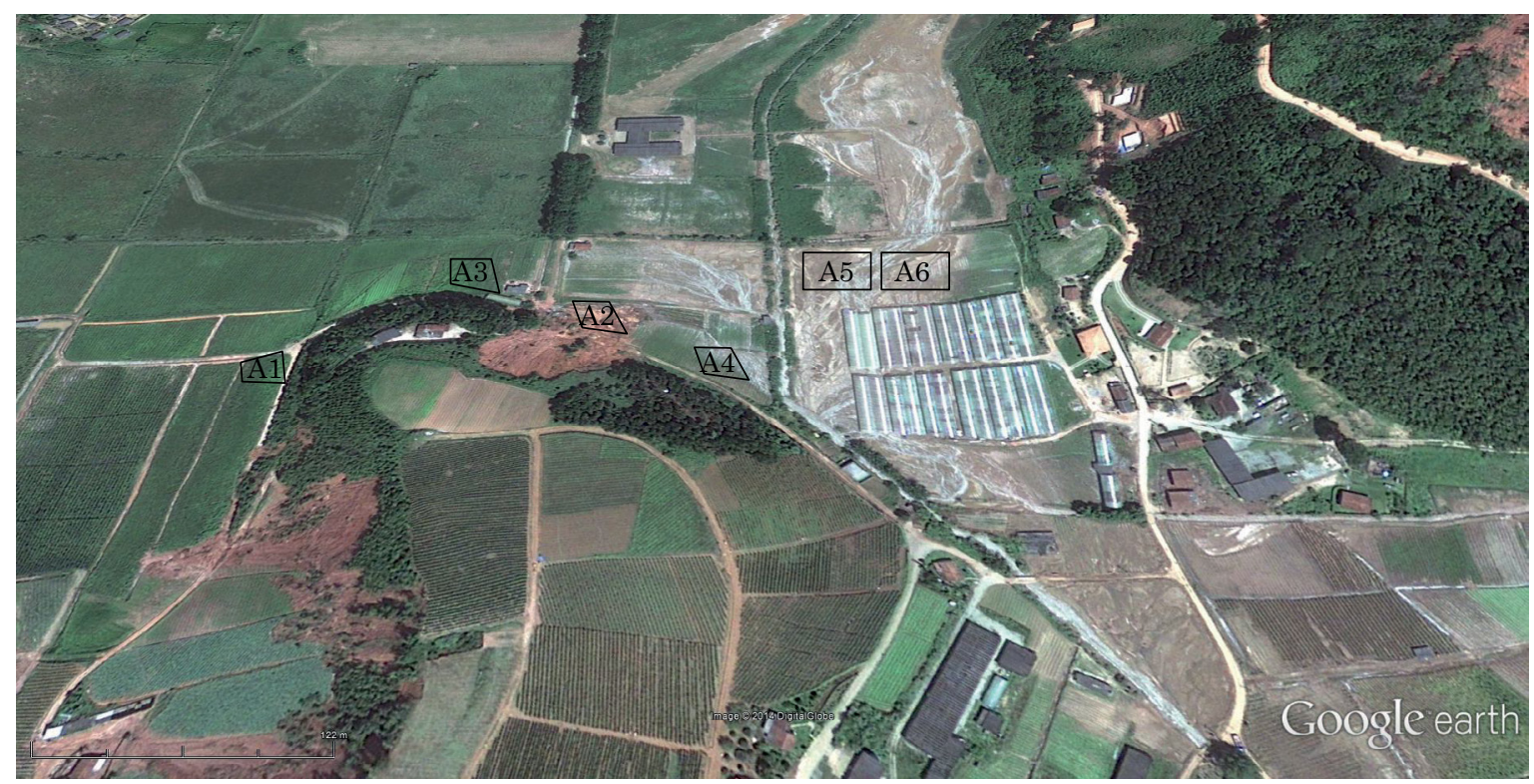

Figura 1. Localização das áreas de estudo na Comunidade Fazenda Rio Grande, Nova Friburgo, RJ. Fonte: Google Earth. 
Quadro 1. Caracterização das áreas selecionadas para o estudo

$\begin{array}{ll}\begin{array}{l}\text { Identificação } \\ \text { da área }\end{array} & \text { Descrição da área }\end{array}$

$\mathrm{A} 1$

Área de cultivo tradicional de olerícolas, que não foi impactada por deslizamento de terra e por inundação em janeiro de 2011. Na época da amostragem, estava em pousio, com a presença de vegetação espontânea, principalmente gramínea (S $22^{\circ} 17^{\prime} 15^{\prime \prime}$ e W $\left.42^{\circ} 39^{\prime} 36,6^{\prime \prime}\right)$

A2

Impacto por deslizamento de barreira muito intenso, causando soterramento total da área em janeiro de 2011. Após a limpeza da área, realizaram-se calagem $\left(1,5 \mathrm{Mg} \mathrm{ha}^{-1}\right)$, adubação com cama de aviário $\left(15 \mathrm{Mg} \mathrm{ha}^{-1}\right) \mathrm{e}$ formulado NPK 4-14-8 (1 Mg ha ${ }^{-1}$ ); fez-se o pré-cultivo de inverno com aveia-preta (Avena strigosa) e ervilhaca (Vicia sativa), para o cultivo em sequência de três hortaliças em plantio direto. Essa sucessão cultural de adubos verdes e hortaliças e adubação foi repetida em 2012/13 (S $22^{\circ} 17^{\prime} 11,9^{\prime \prime}$ e W $\left.42^{\circ} 39^{\prime} 33,8^{\prime \prime}\right)$.

A3

Impacto causado por transbordamento do rio em janeiro de 2011. A área permaneceu um mês inundada. Após, essa teve tratamento semelhante ao da A2, diferindo apenas nas plantas de cobertura utilizadas: milheto (Penissetum americanum) e girassol (Helianthus annuus) (S $22^{\circ} 17^{\prime} 11^{\prime \prime}$ e W $42^{\circ} 39^{\prime} 30,0^{\prime \prime}$.

A4

Impacto causado por transbordamento do rio em janeiro de 2011, permanecendo 2 meses inundada com grande deposição de areia. Após esse período, recebeu adubação com cama de aviário $\left(15 \mathrm{Mg} \mathrm{ha}{ }^{-1}\right)$ e formulado NPK 4-14-8 (1 $\left.\mathrm{Mg} \mathrm{ha}^{-1}\right)$ e foi cultivada em plantio direto com cobertura de aveia-preta (Avena strigosa) (S $22^{\circ} 17^{\prime} 9,1^{\prime \prime} \mathrm{e}$ W $\left.42^{\circ} 39^{\prime} 32,3^{\prime \prime}\right)$

A5

Impacto causado por transbordamento do rio em janeiro de 2011. A área permaneceu dois meses inundada com grande deposição de areia. Após o episódio, o agricultor preparou a área com aração e gradagem e realizou calagem $\left(1,5 \mathrm{Mg} \mathrm{ha}^{-1}\right)$ e adubação com cama de aviário $\left(15 \mathrm{Mg} \mathrm{ha}^{-1}\right)$, formulado NPK 4-14-8 (1 Mg ha $\left.{ }^{-1}\right)$ e Yoorim $\left(1,5 \mathrm{Mg} \mathrm{ha}^{-1}\right)$ para os cultivos de aipo (Apium graveolens) e acelga (Beta vulgaris var. cicla). O rendimento das culturas foi inferior em mais de $50 \%$ ao que obtinha anteriormente na mesma área, inviabilizando o cultivo comercial. Desde então, até a época da amostragem a área não foi cultivada. (S $22^{\circ} 17^{\prime} 7,3^{\prime \prime}$ e W $42^{\circ} 39^{\prime} 30,9$ ”).

A6

Área com mesmo histórico da A5, porém com menor impacto da inundação; solos com horizonte glei (tabatinga) (S $22^{\circ} 17^{\prime} 6,5^{\prime \prime}$ e W $\left.42^{\circ} 39^{\prime} 30,3 ”\right)$.

variâncias. A partir da constatação de atendimento dos pressupostos básicos da ANOVA, as médias dos dados foram comparadas entre si pelo teste t a $5 \%$, com auxílio do programa Assistat (Silva e Azevedo, 2002). Além disso, utilizou-se análise de componentes principais (ACP), visando melhor interpretação do padrão dos solos em razão dos teores de matéria orgânica, utilizando o programa XL Stat e análise de correlação de Pearson pelo programa Excel (Microsoft). Para a ACP, consideraram-se as profundidades 0,00-0,05 e 0,05-0,10 m.

\section{RESULTADOS E DISCUSSÃO}

A composição granulométrica do solo variou conforme o impacto que a região foi submetida. A área onde ocorreu o deslizamento de barreira (A2) apresentou distribuição homogênea de argila em relação às profundidades avaliadas. As áreas que permaneceram alagadas por dois meses (A4, A5 e A6) evidenciaram os mais baixos valores de argila, possivelmente por essa ter sido transportada para outras partes da paisagem; o teor de argila da área mais próxima do rio aumentou com a profundidade. Evento oposto ao que ocorre na área testemunha e outras áreas não impactadas (Quadro 2).

A densidade do solo das áreas avaliadas atingiu valores entre 0,71 e $1,02 \mathrm{Mg} \mathrm{m}^{-3}$, não sendo um fator que representa restrição ao desenvolvimento do sistema radicular das culturas (Quadro 3). A restrição ocorre para culturas comerciais, quando a densidade fica acima de $1,45 \mathrm{Mg} \mathrm{m}^{-3}$ em solos argilosos e $1,65 \mathrm{Mg} \mathrm{m}^{-3}$ em solos arenosos (Reinert e Reichert, 2001).

As áreas A1, A2 e A4 apresentaram os maiores valores de densidade na profundidade de 0,00-0,05 m com valores entre 0,84 e $0,88 \mathrm{Mg} \mathrm{m}^{-3}(\mathrm{p}<0,05)$; e as A1 e A2, os maiores valores nas profundidades de 0,05-0,10 e 0,10-0,20 m com valores entre 0,92 e $0,99 \mathrm{Mg} \mathrm{m}^{-3}(\mathrm{p}<0,05)$. Apesar dos altos teores de areia nas áreas A4 e A5, não foram observados aumentos na Ds com valores entre 0,85 e $0,92 \mathrm{Mg} \mathrm{m}^{-3}$ e 0,71 e $0,91 \mathrm{Mg} \mathrm{m}^{-3}$ para essas áreas, respectivamente, até $0,20 \mathrm{~m}$ de profundidade. Esse resultado evidencia que mesmo nessa condição o solo apresenta estrutura que favorece o desenvolvimento adequado do sistema radicular.

Estudando os atributos edáficos em áreas sob manejo orgânico e natural na região Serrana do Estado do Rio de Janeiro, Cardozo et al. (2008) verificaram valores de Ds significativamente maiores na área de cultivo $\left(0,83 \mathrm{e} 0,84 \mathrm{Mg} \mathrm{m}^{-3}\right)$, quando comparados aos da área de floresta secundária $(0,64$ a $0,59 \mathrm{Mg} \mathrm{m}^{-3}$ ). Em Latossolo Vermelho-Amarelo em diferentes tipos de uso da terra (pastagem, mata de eucalipto, mata com araucária, plantio convencional com cenoura e abóbora), na Serra da Mantiqueira, MG, Melloni et al. (2013) constataram maiores valores de Ds nas áreas de cultivo convencional com cenoura $\left(1,24 \mathrm{Mg} \mathrm{m}^{-3}\right)$, abóbora $\left(1,21 \mathrm{Mg} \mathrm{m}^{-3}\right)$ seguida da área de pastagem $\left(1,17 \mathrm{Mg} \mathrm{m}^{-3}\right)$ e nas matas de araucária $\left(1,01 \mathrm{Mg} \mathrm{m}^{-3}\right)$ e eucalipto $\left(0,88 \mathrm{Mg} \mathrm{m}^{-3}\right)$. 
Quadro 2. Composição granulométrica e classe textural das seis áreas estudadas, nas três profundidades avaliadas, após impacto ambiental

\begin{tabular}{|c|c|c|c|c|c|c|}
\hline Atributo & A1 & A2 & A3 & A4 & A5 & A6 \\
\hline & \multicolumn{6}{|c|}{$0,00-0,05 \mathrm{~m}$} \\
\hline Argila & 210 & 250 & 393 & 60 & 130 & 226 \\
\hline Areia & 560 & 540 & 416 & 783 & 713 & 530 \\
\hline Silte & 230 & 210 & 191 & 157 & 157 & 244 \\
\hline \multirow[t]{2}{*}{ Classe textural } & Franca & Franca & Franco-argilosa & Franco-arenosa & Franco-arenosa & Franca \\
\hline & \multicolumn{6}{|c|}{$0,05-0,10 \mathrm{~m}$} \\
\hline Argila & 170 & 253 & 300 & 100 & 160 & 193 \\
\hline Areia & 533 & 466 & 503 & 780 & 673 & 563 \\
\hline Silte & 297 & 281 & 197 & 120 & 167 & 244 \\
\hline \multirow[t]{2}{*}{ Classe Textural } & Franco-siltosa & Franco-siltosa & Franco-argilosa & Franco-arenosa & Franco-arenosa & Franco \\
\hline & \multicolumn{6}{|c|}{$0,10-0,20 \mathrm{~m}$} \\
\hline Argila & 153 & 256 & 263 & 143 & 166 & 146 \\
\hline Areia & 580 & 440 & 450 & 716 & 656 & 646 \\
\hline Silte & 267 & 304 & 287 & 141 & 178 & 208 \\
\hline Classe Textural & Franca & Franco-siltosa & Franco-siltosa & Franco-arenosa & Franca & Franca \\
\hline
\end{tabular}

1: Sem impacto; 2: soterramento total e cultivo de aveia+ervilhaca; 3: transbordamento do rio e cultivo de milheto+girassol; 4: transbordamento do rio e grande deposição de areia cultivo de aveia-preta; 5: transbordamento do rio o que ocasionou grande deposição de areia e sem cultivo; e 6: transbordamento do rio em menor escala e sem cultivo.

Quadro 3. Densidade do solo (Ds) e densidade de partículas (Dp) das áreas estudadas, nas três profundidades avaliadas, após impacto ambiental

\begin{tabular}{|c|c|c|c|c|c|c|}
\hline \multirow{2}{*}{$\operatorname{Área}^{(1)}$} & \multicolumn{3}{|c|}{ Ds $\left(\mathrm{Mg} \mathrm{m}^{-3}\right)$} & \multicolumn{3}{|c|}{$\mathrm{Dp}\left(\mathrm{Mg} \mathrm{m}^{-3}\right)$} \\
\hline & $0,00-0,05 \mathrm{~m}$ & $0,05-0,10 \mathrm{~m}$ & $0,10-0,20 \mathrm{~m}$ & $0,00-0,05 \mathrm{~m}$ & $0,05-0,10 \mathrm{~m}$ & $0,10-0,20 \mathrm{~m}$ \\
\hline $\mathrm{A} 1$ & $0,88 \mathrm{~A}$ & $0,99 \mathrm{~A}$ & $1,02 \mathrm{~A}$ & $2,11 \mathrm{C}$ & $2,17 \mathrm{BC}$ & $2,15 \mathrm{~B}$ \\
\hline A2 & $0,84 \mathrm{~A}$ & $0,92 \mathrm{AB}$ & $1,01 \mathrm{AB}$ & $2,27 \mathrm{~B}$ & $2,13 \mathrm{BC}$ & $2,16 \mathrm{AB}$ \\
\hline A3 & $0,73 \mathrm{~B}$ & $0,79 \mathrm{C}$ & $0,85 \mathrm{C}$ & $2,06 \mathrm{C}$ & $2,01 \mathrm{C}$ & $2,02 \mathrm{~B}$ \\
\hline A4 & $0,85 \mathrm{~A}$ & $0,85 \mathrm{C}$ & $0,92 \mathrm{BC}$ & $2,50 \mathrm{~A}$ & $2,33 \mathrm{~A}$ & $2,33 \mathrm{~A}$ \\
\hline A5 & $0,71 \mathrm{~B}$ & $0,78 \mathrm{C}$ & $0,91 \mathrm{C}$ & $2,33 \mathrm{~B}$ & $2,25 \mathrm{AB}$ & $2,10 \mathrm{~B}$ \\
\hline A6 & $0,73 \mathrm{~B}$ & $0,85 \mathrm{BC}$ & $0,84 \mathrm{~B}$ & $2,18 \mathrm{BC}$ & $2,09 \mathrm{BC}$ & $2,04 \mathrm{~B}$ \\
\hline CV (\%) & 11,73 & 7,23 & 8,49 & 4,07 & 4,38 & 4,46 \\
\hline
\end{tabular}

1: Sem impacto; 2: soterramento total e cultivo de aveia+ervilhaca; 3: transbordamento do rio e cultivo de milheto+girassol; 4: transbordamento do rio e grande deposição de areia e cultivo de aveia-preta; 5: transbordamento do rio, o que ocasionou grande deposição de areia e sem cultivo; 6: transbordamento do rio em menor escala e sem cultivo. Médias seguidas de mesma letra, na mesma coluna, não diferem entre si pelo teste $t(p<0,05)$.

A densidade de partículas (Dp) é um atributo inerente ao solo; a variação dessa ocorre em razão da mineralogia e do teor de matéria orgânica. Solos minerais comumente encontrados no Brasil apresentam Dp com média de $2,65 \mathrm{Mg} \mathrm{m}^{-3}$, refletindo a presença dominante de quartzo, feldspatos e silicatos (Ferreira, 2010). Contudo, nesse estudo, independentemente da área, foram encontrados valores de $\mathrm{Dp}$ abaixo dessa média, entre 2,01 e $2,50 \mathrm{Mg} \mathrm{m}^{-3}$, sendo os maiores quantificados na área 4 até $0,20 \mathrm{~m}$ de profundidade. Assim, pode-se inferir que isso é reflexo da maior adição de MO por consequência do manejo (massa específica média de $\left.1,20 \mathrm{Mg} \mathrm{m}^{-3}\right)$. Valores de Dp médios de 2,17 a $2,32 \mathrm{Mg} \mathrm{m}^{-3}$ foram observados por Melloni et al. (2013), os quais atribuíram essa diminuição da Dp aos teores de matéria orgânica encontrados nas áreas.

\section{Índices de agregação e distribuição da massa de agregados estáveis em água}

No que se refere aos índices de estabilidade de agregados estáveis em água - diâmetro médio ponderado (DMP) e diâmetro médio geométrico (DMG) - verificaram-se diferenças entre as áreas estudadas (Quadro 4). A área A4 apresentou o menor valor de DMP, variando entre 1,78 e $2,20 \mathrm{~mm}$ 
nas profundidades de 0,00-0,05 e 0,05-0,10 m, respectivamente. Na profundidade de 0,00-0,05 m, não se verificaram diferenças entre as demais áreas estudadas. Para a profundidade de 0,05-0,10 m, a área A6 foi a que expressou o maior valor de DMP, com $4,34 \mathrm{~mm}$, o que reflete a resistência do solo à erosão. As áreas anteriormente citadas foram as que receberam menor impacto. $\mathrm{O}$ valor de DMG observado na área $\mathrm{A} 4$ pode estar relacionado à textura arenosa dela, que desfavorece a agregação pelo maior teor de areia. Para o DMG na profundidade de 0,00-0,05 m, os maiores valores foram expressos nas áreas A2, A3, e A6, seguindo o mesmo padrão do DMP. Na profundidade de 0,05-0,10 m, a área 6 evidenciou valores superiores às outras áreas estudadas.

Em Argissolo Vermelho-Amarelo com cultivo de hortaliças, Cardozo et al. (2008) quantificaram valores de DMP entre 3,36 e $3,42 \mathrm{~mm}$, valores inferiores quando comparados à área com floresta secundária com valores médios de 4,10, apresentando maior estabilidade nos sistemas naturais. Estudando atributos químicos e físicos do solo em diferentes sistemas de preparo do solo (cobertura com gramínea, plantio direto, plantio

Quadro 4. Diâmetro médio ponderado (DMP) e diâmetro médio geométrico (DMG) de agregados das áreas estudadas, nas duas profundidades avaliadas, após impacto ambiental

\begin{tabular}{|c|c|c|}
\hline Área & DMP & DMG \\
\hline & \multicolumn{2}{|c|}{$\mathrm{mm}$} \\
\hline & \multicolumn{2}{|c|}{$0,00-0,05 \mathrm{~m}$} \\
\hline A1 & $3,16 \mathrm{~A}$ & $2,39 \mathrm{AB}$ \\
\hline $\mathrm{A} 2$ & $3,40 \mathrm{~A}$ & $3,15 \mathrm{~A}$ \\
\hline A3 & $4,00 \mathrm{~A}$ & $2,65 \mathrm{~A}$ \\
\hline A4 & $1,78 \mathrm{~B}$ & $1,15 \mathrm{C}$ \\
\hline A5 & $2,99 \mathrm{~A}$ & $1,59 \mathrm{BC}$ \\
\hline A6 & $3,91 \mathrm{~A}$ & $2,87 \mathrm{~A}$ \\
\hline \multirow[t]{2}{*}{ CV (\%) } & 18,60 & 24,93 \\
\hline & \multicolumn{2}{|c|}{$0,05-0,10 \mathrm{~m}$} \\
\hline $\mathrm{A} 1$ & $3,16 \mathrm{~A}$ & $2,39 \mathrm{AB}$ \\
\hline $\mathrm{A} 2$ & $3,40 \mathrm{~A}$ & $3,15 \mathrm{~A}$ \\
\hline A3 & $4,00 \mathrm{~A}$ & $2,65 \mathrm{~A}$ \\
\hline A4 & $1,78 \mathrm{~B}$ & $1,15 \mathrm{C}$ \\
\hline A5 & $2,99 \mathrm{~A}$ & $1,59 \mathrm{BC}$ \\
\hline A6 & $3,91 \mathrm{~A}$ & $2,87 \mathrm{~A}$ \\
\hline CV (\%) & 18,60 & 24,93 \\
\hline
\end{tabular}

1: Sem impacto; 2 : soterramento total e cultivo de aveia+ervilhaca 3: transbordamento do rio e cultivo de milheto+girassol; 4: transbordamento do rio e grande deposição de areia e cultivo de aveia-preta; 5: transbordamento do rio, o que ocasionou grande deposição de areia e sem cultivo; 6 : transbordamento do rio em menor escala e sem cultivo. Médias seguidas de mesma letra, na mesma coluna, não diferem entre si pelo teste $t(p<0,05)$. convencional, cultivo em contorno com tração animal e solo descoberto) para cultivo de oleráceas em Paty do Alferes, RJ, Pinheiro et al. (2004) e Turetta (2000) observaram maiores valores de DMP e DMG nos sistemas com solo com cobertura de gramínea e plantio direto e menores valores dos dois atributos na área com solo descoberto, evidenciando que onde ocorreram menor intensidade nas práticas de cultivo e maior taxa de adição de material foram encontrados os maiores valores de DMP e menores valores de densidade do solo.

Em estudos sobre atributos químicos e físicos de um Argissolo Vermelho-Amarelo em sistema integrado de produção agroecológica, Loss et al. (2009) encontraram maiores valores de DMP no sistema de plantio direto (PD) com cultivo de berinjela+feijão, quando comparados ao plantio convencional de milho+feijão nas profundidades de 0,00-0,05 e 0,05-0,10 $\mathrm{m}$ e nas duas épocas de amostragem, verão e inverno. Tanto o sistema de $\mathrm{PD}$ como o de plantio convencional utilizaram a mesma rotação de cultura anteriormente com milho (Zea mays), feijão (Phaseolus vulgaris), quiabo (Abelmoschus esculentus) e couve (Brassica oleracea). O sistema de PD propicia manutenção dos resíduos vegetais na superfície do solo, assim como os maiores valores de COT e a maior estabilidade dos agregados. Áreas com maior aporte de material vegetal e com menor interferência antrópica apresentaram maior agregação com maiores valores de DMP e DMG, como constatado por Loss et al. (2011), ao avaliarem a estabilidade de agregados de um Latossolo Vermelho argiloso sob sistema PD com ou sem integração lavoura-pecuária, em comparação à área de Cerrado natural, em Goiás, e por Melloni et al. (2013), ao analisarem a qualidade microbiana dos agregados de um Latossolo Vermelho-Amarelo com diferentes tipos de uso da terra na Serra da Mantiqueira, MG.

\section{Avaliação da fertilidade do solo}

As áreas apresentaram, de maneira geral, boa disponibilidade de nutrientes e ausência de elementos tóxicos (Quadro 5). Esse padrão pode ser decorrente de as áreas serem utilizadas com o cultivo intensivo de hortaliças, que possuem ciclos curtos e são adubadas periodicamente. Todas as áreas apresentaram valores de $\mathrm{pH}$ acima de 5,0, com destaque para a área $\mathrm{A} 2$, onde quantificaram-se valores superiores a 7,4 até $0,10 \mathrm{~m}$ de profundidade. Em razão dos altos valores de $\mathrm{pH}$, não se verificou a presença de $\mathrm{Al}^{3+}$ nas áreas avaliadas. Todas as áreas também revelaram altos valores de soma de bases, com destaque para as A2, $\mathrm{A} 3 \mathrm{e}$ A6. Os menores valores de $\mathrm{V}$ foram quantificados na área $\mathrm{A} 1$, na profundidade de 0,00-0,05 m, e na A4, nas profundidades de 0,05-0,10 e 0,10-0,20 m. Em nenhuma das áreas o valor de $\mathrm{V}$ foi inferior a $50 \%$, o que caracteriza as áreas como eutróficas. Variação no valor de $\mathrm{pH}$ entre 4,82 e 5,09 em área de cultivo de oleráceas e 4,15 a 4,54 na área testemunha (mata 
Quadro 5. Atributos químicos das áreas estudadas, nas profundidades avaliadas, após impacto ambiental

\begin{tabular}{|c|c|c|c|c|c|c|c|c|c|c|c|}
\hline Área & $\mathrm{pH}\left(\mathrm{H}_{2} \mathrm{O}\right)$ & $\mathrm{Al}^{3+}$ & $\mathrm{H}+\mathrm{Al}$ & $\mathrm{Ca}^{2+}$ & $\mathrm{Ca}^{2+}+\mathrm{Mg}^{2+}$ & $\mathrm{Na}^{+}$ & SB & $\mathbf{T}$ & $\mathrm{V}$ & $\mathbf{K}$ & $\mathbf{P}$ \\
\hline & & \multicolumn{7}{|c|}{$\mathrm{cmol}_{\mathrm{c}} \mathrm{kg}^{-1}$} & $\%$ & \multicolumn{2}{|c|}{$\mathrm{mg} \mathrm{kg}^{-1}$} \\
\hline & & & & & & $00-0,05 \mathrm{~m}$ & & & & & \\
\hline $\mathrm{A} 1$ & $5,4 \mathrm{C}$ & $0^{\mathrm{ns}}$ & $5,0 \mathrm{~A}$ & $3,5 \mathrm{~B}$ & $5,0 \mathrm{~B}$ & $0,10 \mathrm{AB}$ & $5,6 \mathrm{~B}$ & $10,6 \mathrm{AB}$ & $52,8 \mathrm{D}$ & $175,5 \mathrm{AB}$ & $11,3 \mathrm{~B}$ \\
\hline $\mathrm{A} 2$ & $7,5 \mathrm{~A}$ & $0^{\text {ns }}$ & $1,0 \mathrm{C}$ & $4,8 \mathrm{~A}$ & $7,3 \mathrm{~A}$ & $0,20 \mathrm{AB}$ & $8,4 \mathrm{~A}$ & 9,4 BC & $89,5 \mathrm{~A}$ & $374,4 \mathrm{~A}$ & $27,2 \mathrm{~B}$ \\
\hline A3 & $5,6 \mathrm{C}$ & $0^{\text {ns }}$ & $4,5 \mathrm{~A}$ & $4,4 \mathrm{~A}$ & $6,6 \mathrm{~A}$ & $0,02 \mathrm{~B}$ & $7,3 \mathrm{~A}$ & $11,7 \mathrm{~A}$ & $62,1 \mathrm{CD}$ & $250,9 \mathrm{AB}$ & $21,1 \mathrm{~B}$ \\
\hline A4 & $6,2 \mathrm{~B}$ & $0^{\text {ns }}$ & $2,5 \mathrm{~B}$ & $2,2 \mathrm{C}$ & $3,5 \mathrm{C}$ & $0,03 \mathrm{~B}$ & $4,0 \mathrm{~B}$ & $6,5 \mathrm{D}$ & $63,7 \mathrm{C}$ & $167,7 \mathrm{AB}$ & $41,2 \mathrm{~B}$ \\
\hline A5 & $6,1 \mathrm{~B}$ & $0^{\text {ns }}$ & $2,5 \mathrm{~B}$ & $2,4 \mathrm{C}$ & $4,2 \mathrm{BC}$ & $0,04 \mathrm{~B}$ & $4,7 \mathrm{BC}$ & 7,2 CD & $65,1 \mathrm{C}$ & $192,4 \mathrm{AB}$ & $37,5 \mathrm{~B}$ \\
\hline A6 & $6,4 \mathrm{~B}$ & $0^{\text {ns }}$ & $2,4 \mathrm{~B}$ & $5,1 \mathrm{~A}$ & $7,6 \mathrm{~A}$ & $0,10 \mathrm{AB}$ & $8,0 \mathrm{~A}$ & $10,5 \mathrm{~A}$ & $76,6 \mathrm{~B}$ & $161,2 \mathrm{~B}$ & $268,5 \mathrm{~A}$ \\
\hline \multirow[t]{2}{*}{ CV (\%) } & 3,4 & & 23,3 & 9,9 & 12,2 & 34,8 & 14,4 & 14,0 & 7,6 & 53,0 & 23,1 \\
\hline & \multicolumn{11}{|c|}{$0,05-0,10 \mathrm{~m}$} \\
\hline $\mathrm{A} 1$ & $5,0 \mathrm{E}$ & $0^{\text {ns }}$ & $2,2 \mathrm{BC}$ & $1,3 \mathrm{D}$ & $3,3 \mathrm{C}$ & 0,02 B & $3,5 \mathrm{C}$ & $5,7 \mathrm{C}$ & $61,1 \mathrm{D}$ & 89,7 B & $19,8 \mathrm{~B}$ \\
\hline $\mathrm{A} 2$ & $7,4 \mathrm{~A}$ & $0^{\text {ns }}$ & $0,7 \mathrm{D}$ & $4,0 \mathrm{~B}$ & $6,2 \mathrm{~B}$ & $0,10 \mathrm{AB}$ & $6,8 \mathrm{~B}$ & $7,5 \mathrm{~B}$ & $90,0 \mathrm{~A}$ & $210,6 \mathrm{AB}$ & $3,5 \mathrm{~B}$ \\
\hline A3 & $6,3 \mathrm{~B}$ & $0^{\text {ns }}$ & $3,0 \mathrm{~A}$ & $4,8 \mathrm{~A}$ & $6,6 \mathrm{~B}$ & $0,02 \mathrm{~B}$ & $7,4 \mathrm{AB}$ & $10,4 \mathrm{~A}$ & $71,2 \mathrm{C}$ & $304,2 \mathrm{~A}$ & $15,4 \mathrm{~B}$ \\
\hline A4 & $5,5 \mathrm{D}$ & $0^{\text {ns }}$ & $2,2 \mathrm{BC}$ & $1,5 \mathrm{CD}$ & $2,7 \mathrm{C}$ & $0,02 \mathrm{~B}$ & $3,3 \mathrm{C}$ & $5,5 \mathrm{C}$ & $59,9 \mathrm{D}$ & $222,3 \mathrm{AB}$ & $27,1 \mathrm{~B}$ \\
\hline A5 & $5,9 \mathrm{C}$ & $0^{\mathrm{ns}}$ & $2,4 \mathrm{~B}$ & $2,3 \mathrm{C}$ & $3,3 \mathrm{C}$ & $0,02 \mathrm{~B}$ & $3,8 \mathrm{C}$ & $6,2 \mathrm{C}$ & $60,8 \mathrm{D}$ & $197,6 \mathrm{AB}$ & $48,5 \mathrm{~B}$ \\
\hline A6 & $6,5 \mathrm{~B}$ & $0^{\text {ns }}$ & $1,9 \mathrm{C}$ & $5,2 \mathrm{~A}$ & $7,8 \mathrm{~A}$ & $0,10 \mathrm{AB}$ & $8,5 \mathrm{~A}$ & $10,4 \mathrm{~A}$ & $81,9 \mathrm{~B}$ & $245,7 \mathrm{AB}$ & $311,3 \mathrm{~A}$ \\
\hline \multirow[t]{2}{*}{ CV (\%) } & 3,1 & & 11,3 & 13,5 & 10,5 & 33,5 & 12,1 & 8,7 & 6,0 & 41,5 & 29,7 \\
\hline & \multicolumn{11}{|c|}{$0,10-0,20 \mathrm{~m}$} \\
\hline $\mathrm{A} 1$ & $5,3 \mathrm{C}$ & $0^{\mathrm{ns}}$ & $2,0 \mathrm{C}$ & $1,9 \mathrm{C}$ & $3,1 \mathrm{~B}$ & 0,01 C & $3,4 \mathrm{~B}$ & $5,3 \mathrm{D}$ & $63,6 \mathrm{BC}$ & $123,5 \mathrm{~B}$ & $3,5 \mathrm{~B}$ \\
\hline $\mathrm{A} 2$ & $6,8 \mathrm{~A}$ & $0^{\text {ns }}$ & $1,4 \mathrm{D}$ & $2,7 \mathrm{~B}$ & $4,5 \mathrm{~B}$ & $0,23 \mathrm{AB}$ & $5,5 \mathrm{BC}$ & 6,9 CD & $78,5 \mathrm{~A}$ & $312,0 \mathrm{AB}$ & $20,2 \mathrm{~B}$ \\
\hline A3 & $6,4 \mathrm{AB}$ & $0^{\text {ns }}$ & $2,4 \mathrm{~B}$ & $5,4 \mathrm{~A}$ & $7,5 \mathrm{~A}$ & 0,03 BC & $8,2 \mathrm{~A}$ & $10,7 \mathrm{~A}$ & $77,4 \mathrm{~A}$ & $292,5 \mathrm{AB}$ & $40,1 \mathrm{~B}$ \\
\hline A4 & $5,4 \mathrm{C}$ & $0^{\text {ns }}$ & $3,0 \mathrm{~A}$ & $1,9 \mathrm{C}$ & $3,2 \mathrm{~B}$ & $0,02 \mathrm{BC}$ & $3,9 \mathrm{BC}$ & $6,9 \mathrm{CD}$ & $57,1 \mathrm{C}$ & $280,8 \mathrm{AB}$ & $27,1 \mathrm{~B}$ \\
\hline A5 & $6,0 \mathrm{~B}$ & $0^{\text {ns }}$ & $2,7 \mathrm{~A}$ & $2,7 \mathrm{~B}$ & $4,6 \mathrm{~B}$ & $0,02 \mathrm{BC}$ & $5,6 \mathrm{~B}$ & $8,4 \mathrm{BC}$ & $66,9 \mathrm{~B}$ & $409,5 \mathrm{~A}$ & $46,0 \mathrm{~B}$ \\
\hline A6 & $6,8 \mathrm{~A}$ & $0^{\text {ns }}$ & $1,5 \mathrm{D}$ & $5,3 \mathrm{~A}$ & $8,2 \mathrm{~A}$ & $0,10 \mathrm{~B}$ & $8,6 \mathrm{~A}$ & $10,0 \mathrm{AB}$ & $85,6 \mathrm{~A}$ & $122,2 \mathrm{~B}$ & $303,2 \mathrm{~A}$ \\
\hline CV (\%) & 4,6 & & 6,4 & 12,3 & 18,9 & 53,4 & 20,8 & 14,8 & 6,5 & 18,9 & 21,0 \\
\hline
\end{tabular}

1: Sem impacto; 2: soterramento total e cultivo de aveia+ervilhaca; 3: transbordamento do rio e cultivo de milheto+girassol; 4: transbordamento do rio e grande deposição de areia cultivo de aveia-preta; 5: transbordamento do rio, o que ocasionou grande deposição de areia e sem cultivo; 6 : transbordamento do rio em menor escala e sem cultivo. Médias seguidas de mesma letra, na mesma coluna, não diferem entre si pelo teste $\mathrm{t}(\mathrm{p}<0,05)$. SB: soma de bases; T: capacidade de troca de cátions a pH 7,0; V: saturação por bases.

nativa), foi evidenciado por Cardozo et al. (2008), que constataram maiores valores médios para a área em cultivo, nas profundidades de 0,05-0,10 e 0,10-0,20 m. Segundo os autores, esse padrão decorre dos maiores teores de bases encontrados na área em cultivo e da forma de manejo (orgânico), que está beneficiando o aumento do $\mathrm{pH}$ quando comparado à área testemunha.

Os valores de $\mathrm{P}$ e $\mathrm{K}$ foram superiores aos níveis de suficiência para o cultivo da maioria das culturas de interesse comercial. Para as hortaliças, valores acima de $30 \mathrm{mg} \mathrm{kg}{ }^{-1}$ de $\mathrm{P}$ e $135 \mathrm{mg} \mathrm{kg}^{-1}$ de $\mathrm{K}$ são considerados muito altos, segundo as classes de interpretação estabelecidas para os dois nutrientes, de acordo com o Manual de Calagem e Adubação do Estado do Rio de Janeiro (Portz et al., 2013).

Valores de P extremamente altos foram observados na área $\mathrm{A} 6$ acima de $250 \mathrm{mg} \mathrm{kg}^{-1}$ para as profundidades avaliadas. Para o K, com exceção da área $\mathrm{A} 1$, nas profundidades de 0,05-0,10 e 0,10-0,20 m, os valores foram considerados altos; para as demais áreas e profundidades foram quantificados valores extremamente altos desse elemento. Adicionalmente, os elevados teores de Kobservados podem desfavorecer a absorção de $\mathrm{Mg}^{2+}$ e de $\mathrm{Ca}^{2+}$ em menor proporção. Teor elevado de $\mathrm{K}$ em áreas com cultivo orgânico com oleráceas, entre 128,7 e $191,1 \mathrm{mg} \mathrm{kg}^{-1}$, e na área de floresta secundária, 46,8 a $62,4 \mathrm{mg} \mathrm{kg}^{-1}$, foram encontrados por Cardozo et al. (2008). Para P, foram observados baixos teores variando de 2,2 a $2,8 \mathrm{mg} \mathrm{kg}^{-1}$, na área de cultivo orgânico de oleráceas, e de 0,1 a $0,12 \mathrm{mg} \mathrm{kg}^{-1}$, na área de floresta secundária.

\section{Carbono orgânico total, fracionamentos granulométrico e químico da matéria orgânica}

Os teores de carbono orgânico total (COT) apresentaram diferenças entre as áreas avaliadas (Quadro 6). Os maiores teores de COT $(p<0,05)$ 
Quadro 6. Carbono orgânico total (COT), carbono orgânico particulado (COp), carbono orgânico associado aos minerais (Coam), ácido fúlvico (C-FAF), ácido húmico (C-FAH) e humina (C-HUM), das áreas estudadas, nas profundidades avaliadas, após impacto ambiental

\begin{tabular}{|c|c|c|c|c|c|c|}
\hline Área $^{(1)}$ & COT & $\mathrm{COp}$ & COam & C-FAF & C-FAH & C-HUM \\
\hline & \multicolumn{6}{|c|}{$\mathrm{g} \mathrm{kg}^{-1}$} \\
\hline & \multicolumn{6}{|c|}{$0,00-0,05 \mathrm{~m}$} \\
\hline $\mathrm{A} 1$ & $15,4 \mathrm{CD}$ & $11,5 \mathrm{~A}$ & $3,9 \mathrm{C}$ & $3,2 \mathrm{~B}$ & $3,1 \mathrm{~B}$ & $7,9 \mathrm{~B}$ \\
\hline $\mathrm{A} 2$ & $16,5 \mathrm{C}$ & $8,4 \mathrm{~B}$ & $8,2 \mathrm{~B}$ & $2,8 \mathrm{BC}$ & $1,8 \mathrm{D}$ & $10,3 \mathrm{~A}$ \\
\hline A3 & $21,5 \mathrm{~B}$ & $9,0 \mathrm{~B}$ & $12,5 \mathrm{~A}$ & $3,9 \mathrm{~A}$ & $3,9 \mathrm{~A}$ & $11,3 \mathrm{~A}$ \\
\hline $\mathrm{A} 4$ & $12,9 \mathrm{E}$ & $5,1 \mathrm{D}$ & $7,8 \mathrm{~B}$ & $2,2 \mathrm{C}$ & $1,7 \mathrm{D}$ & $4,7 \mathrm{C}$ \\
\hline A5 & $14,7 \mathrm{D}$ & $6,7 \mathrm{C}$ & $7,9 \mathrm{~B}$ & $3,0 \mathrm{~B}$ & $2,3 \mathrm{C}$ & $6,4 \mathrm{~B}$ \\
\hline A6 & $23,5 \mathrm{~A}$ & $9,4 \mathrm{~B}$ & $14,1 \mathrm{~A}$ & $3,1 \mathrm{~B}$ & $4,4 \mathrm{~A}$ & $12,0 \mathrm{~A}$ \\
\hline \multirow[t]{2}{*}{ CV (\%) } & 6,7 & 12,5 & 15,2 & 19,7 & 15,5 & 16,3 \\
\hline & \multicolumn{6}{|c|}{$0,05-0,10 \mathrm{~m}$} \\
\hline $\mathrm{A} 1$ & $11,2 \mathrm{E}$ & $6,4 \mathrm{~B}$ & $4,8 \mathrm{E}$ & $3,0 \mathrm{~B}$ & $2,6 \mathrm{C}$ & $5,9 \mathrm{CD}$ \\
\hline $\mathrm{A} 2$ & $15,4 \mathrm{C}$ & $9,3 \mathrm{~A}$ & 6,2 DE & $2,7 \mathrm{~B}$ & $1,9 \mathrm{D}$ & 9,3 B \\
\hline $\mathrm{A} 3$ & $21,3 \mathrm{~B}$ & $8,9 \mathrm{~A}$ & $12,4 \mathrm{~B}$ & $3,8 \mathrm{~A}$ & $3,6 \mathrm{~B}$ & $11,1 \mathrm{~A}$ \\
\hline $\mathrm{A} 4$ & $13,6 \mathrm{D}$ & $5,5 \mathrm{~B}$ & $8,1 \mathrm{C}$ & $2,0 \mathrm{C}$ & $2,0 \mathrm{D}$ & $4,7 \mathrm{D}$ \\
\hline A5 & $14,0 \mathrm{CD}$ & $6,5 \mathrm{~B}$ & 7,5 CD & $3,0 \mathrm{~B}$ & $1,8 \mathrm{D}$ & $6,5 \mathrm{C}$ \\
\hline $\mathrm{A} 6$ & $23,2 \mathrm{~A}$ & $8,9 \mathrm{~A}$ & $14,4 \mathrm{~A}$ & $3,0 \mathrm{~B}$ & $4,4 \mathrm{~A}$ & $10,7 \mathrm{AB}$ \\
\hline \multirow[t]{2}{*}{ CV (\%) } & 7,9 & 17,9 & 17,6 & 19,3 & 18,1 & 21,6 \\
\hline & \multicolumn{6}{|c|}{$0,10-0,20 \mathrm{~m}$} \\
\hline $\mathrm{A} 1$ & $10,8 \mathrm{D}$ & $5,2 \mathrm{CD}$ & $5,6 \mathrm{C}$ & $3,0 \mathrm{~B}$ & $2,6 \mathrm{~B}$ & $6,1 \mathrm{C}$ \\
\hline $\mathrm{A} 2$ & $13,8 \mathrm{~B}$ & $8,3 \mathrm{AB}$ & $5,6 \mathrm{C}$ & $2,8 \mathrm{BC}$ & $1,7 \mathrm{C}$ & 8,8 B \\
\hline A3 & $21,5 \mathrm{~A}$ & $8,8 \mathrm{AB}$ & $12,7 \mathrm{~A}$ & $3,7 \mathrm{~A}$ & $4,2 \mathrm{~A}$ & $12,0 \mathrm{~A}$ \\
\hline A4 & $13,3 \mathrm{BC}$ & $5,1 \mathrm{D}$ & $8,2 \mathrm{~B}$ & $2,3 \mathrm{C}$ & $2,0 \mathrm{BC}$ & $4,5 \mathrm{C}$ \\
\hline A5 & $11,9 \mathrm{CD}$ & $7,2 \mathrm{BC}$ & $4,7 \mathrm{C}$ & $3,0 \mathrm{~B}$ & $1,6 \mathrm{C}$ & $5,2 \mathrm{C}$ \\
\hline $\mathrm{A} 6$ & $23,2 \mathrm{~A}$ & $9,3 \mathrm{~A}$ & $13,9 \mathrm{~A}$ & $3,0 \mathrm{~B}$ & $4,6 \mathrm{~A}$ & $10,5 \mathrm{~A}$ \\
\hline CV (\%) & 9,1 & 23 & 24,4 & 17,7 & 21,6 & 17,7 \\
\hline
\end{tabular}

1: Sem impacto; 2: soterramento total e cultivo de aveia+ervilhaca; 3: transbordamento do rio e cultivo de milheto+girassol; 4: transbordamento do rio e grande deposição de areia cultivo de aveia-preta; 5: transbordamento do rio, o que ocasionou grande deposição de areia e sem cultivo; 6: transbordamento do rio em menor escala e sem cultivo. Médias seguidas de mesma letra, na mesma coluna, não diferem entre si pelo teste $t(p<0,05)$.

foram verificados na área A6. Das áreas manejadas com plantio direto, a A3 evidenciou diferença nos teores de COT, provavelmente um efeito combinado do processo de deposiçãoassoreamento, com cultivo, preparo do solo e adubação. Os menores valores foram observados na área $\mathrm{A} 4$, que foi submetida ao impacto do transbordamento do rio; esse padrão pode ser atribuído à textura mais grosseira dessa área (Quadro 2). Com exceção da área A4, todas as demais apresentaram valores de COT iguais ou superiores quando comparadas à A1.

Em estudos sobre matéria orgânica do solo sob diferentes coberturas vegetais e cultivadas posteriormente com hortaliças no município de Paty de Alferes, Pinheiro et al. (2004) reportaram maiores valores de COT na área com cobertura de gramínea $\left(21,8 \mathrm{~g} \mathrm{~kg}^{-1}\right)$, seguida pela área com cultivo mínimo $\left(18,5 \mathrm{~g} \mathrm{~kg}^{-1}\right)$; e o menor valor foi encontrado na área com o solo descoberto $\left(6,9 \mathrm{~g} \mathrm{~kg}^{-1}\right)$. Os autores atribuem esse padrão à manutenção dos resíduos culturais no solo. Sistemas como o cultivo mínimo, onde a maior parte dos resíduos permanece na superfície do solo e somente pequena quantidade é incorporada, contribuem para maior proteção da superfície do solo dos processos erosivos e, consequentemente, menor remoção do $\mathrm{C}$ orgânico, juntamente com as partículas minerais (Amado, 1997).

Os valores de estoque de carbono (EstC) foram mais elevados na área $\mathrm{A} 6$, e o menor valor foi observado na área $\mathrm{A} 4$ até $0,10 \mathrm{~m}$ de profundidade (Figura 2). Na profundidade de 0,10-0,20 m, a área A1 apresentou menor EstC em comparação à área 4. Esse padrão por ser atribuído ao cultivo de aveia-preta realizado nessa área, após o transbordamento do rio. O cultivo de gramíneas com sistema radicular melhor distribuído em 


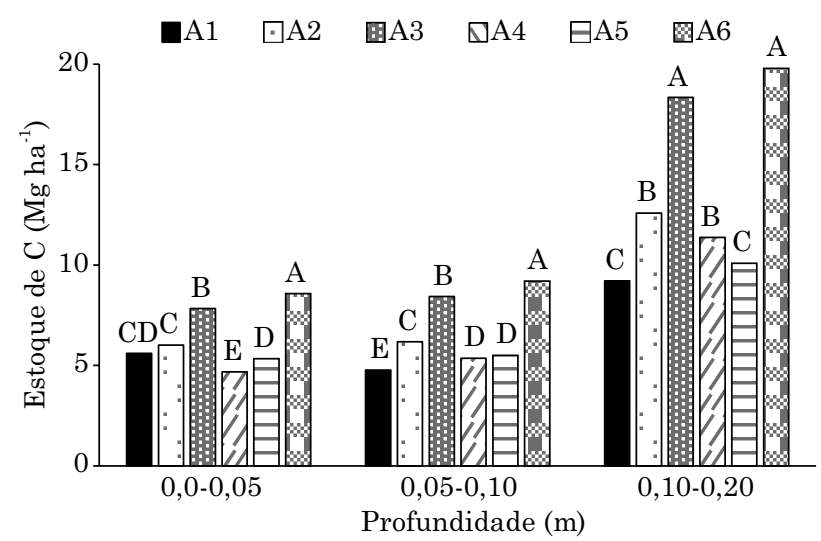

Figura 2. Estoque de carbono (EstC), nas profundidades de $0,00-0,05 ; 0,05-0,10 ; \mathrm{e} 0,10-0,20 \mathrm{~m}$, nas áreas estudadas, após impacto ambiental. 1: Sem impacto; 2: soterramento total e cultivo de aveia+ervilhaca; 3 : transbordamento do rio e cultivo de milheto+girassol; 4 : transbordamento do rio e grande deposição de areia cultivo de aveia-preta; 5: transbordamento do rio, o que ocasionou grande deposição de areia e sem cultivo; 6: transbordamento do rio em menor escala e sem cultivo. Médias seguidas de mesma letra, na mesma coluna, não diferem entre si pelo teste de não diferem entre si pelo teste $\mathrm{t}(\mathrm{p}<0,05)$.

profundidade pode aportar maiores quantidades de $\mathrm{C}$ ao sistema quando comparadas às oleráceas.

O carbono orgânico particulado ( $\mathrm{COp}$ ) é considerado a fração mais lábil e sensível ao manejo, demonstrando que esse compartimento da matéria orgânica pode ser usado como bom indicador de qualidade do solo para avaliar sistemas de manejo recente, onde as alterações no COT do solo ainda não tenham sido de grande magnitude (Conceição et al., 2005). A área A1 usada como testemunha apresentou os maiores valores de $\mathrm{COp}$ na profundidade de 0,00-0,05 m, evidenciando a contribuição constante do aporte de matéria orgânica nessa área promovida pela gramínea que estava nessa área no momento da avaliação.

A menor contribuição da COp para o teor de COT das áreas impactadas está associada principalmente com as formas mais estabilizadas, que possivelmente já ocorriam no material que foi depositado. $\mathrm{O}$ menor valor foi verificado na área A4 na profundidade de 0,00-0,05 m; nessa área, a textura muito arenosa não fornece proteção física para a matéria orgânica. Nas profundidades 0,05-0,10 e 0,10-0,20 m, as áreas A2, A3 e A6 apresentaram valores superiores aos observados na área testemunha (A1).

O carbono orgânico ligado aos minerais (COam), aquele associado às frações silte e argila, apresenta avançado grau de humificação
(Bayer et al., 2004), normalmente é menos sensível às alterações de manejo, principalmente em curto prazo. Os maiores valores da COam foram encontrados na área $\mathrm{A} 6$, coincidentes com os maiores teores de COT. As maiores proporções de COam em relação ao COp ocorreram nas áreas A3 e A6, áreas onde ocorreram os impactos, porém em menor escala quando comparadas às demais, o que sugere maior estabilização do C nessas áreas. Em estudos sobre fracionamentos químico e físico da matéria orgânica de um Argissolo Vermelho em diferentes sistemas de uso no Rio Grande do Sul, Santos et al. (2013b) verificaram que em decorrência do baixo teor de argila do solo a capacidade de proteção da MO é baixa, sendo a formação de agregados estáveis prejudicada pela presença de minerais de tamanho areia. Para esses autores, as maiores proporções relativas de COp são concordantes com a baixa capacidade da fração mineral em manter maior estoque relativo de COam, o que impõe condição de vulnerabilidade do agroecossistema, especialmente se as adições de resíduos culturais forem reduzidas ou sazonais. O padrão observado pelos autores diferiu dos encontrados nesse estudo, já que as áreas A4 e A5 apresentaram maiores teores de areia e maior contribuição da fração COam até a profundidade de $0,10 \mathrm{~m}$.

Quanto às frações químicas da matéria orgânica, houve predomínio da fração humina (C-HUM) em todas as áreas e profundidades avaliadas, seguida da fração ácido fúlvico (C-FAF), com exceção da área 6 , nas profundidades de 0,00-0,05 e 0,05-0,10 m, e das áreas A3 e A6, na profundidade de 0,10-0,20 m, que evidenciaram maiores valores de ácido húmico (C-FAH) (Quadro 6). Esse acúmulo de C-HUM pode ser explicado pelo fato de as huminas serem altamente estáveis e resistentes à degradação microbiana, fortemente associada à fração mineral do solo (Stevenson, 1994; Benites et al., 2003; Barreto et al., 2008), ou em razão de as frações C-FAH e C-FAF serem menos estáveis no solo, sendo submetidas a processos de polimerização e mineralização, com movimentação no perfil do solo (Leite et al., 2003).

Os maiores valores de C-HUM foram verificados nas áreas A6, A2 e A3, até a profundidade de 0-0,05 m, e nas A6 e A3, nas profundidades de 0,05-0,10 e 0,10-0,20 m; e os menores na área A4, na profundidade de 0,00-0,05 m, e nas áreas $\mathrm{A} 4 \mathrm{e}$ A5, nas profundidades de 0,05-0,10 e 0,10-0,20 m. Para a fração C-FAF, o maior valor foi encontrado na área $\mathrm{A} 3 \mathrm{em}$ todas as profundidades avaliadas com valores entre 3,7 e 3,9 $\mathrm{g} \mathrm{kg}^{-1}$, e o menor, na área A4 até $0,10 \mathrm{~m}$ de profundidade. Para a fração C-FAH, os maiores valores foram encontrados nas áreas A3 e A6, nas profundidades de 0,00-0,05 e 0,10-0,20 m, e na área A6, na profundidade de 0,05-0,10 m; e os menores para as áreas A4 e A2, na profundidade de 
0,00-0,05 m, e nas A2, A4 e A5, na profundidade de $0,05-0,10$ e $0,10-0,20 \mathrm{~m}$.

Esses resultados evidenciaram a forte interação do C-HUM com a fração mineral do solo. Com exceção das áreas A4 e A5, nos demais sistemas mais de $50 \%$ do COT estava na forma de C-HUM. $\mathrm{O}$ maior valor de $\mathrm{C}$ na forma de C-HUM favorece as propriedades da fração coloidal da MOS, como: retenção de umidade, melhor agregação do solo e maior retenção de cátions (Souza e Melo, 2003). Em estudos sobre estoques de COT e seus compartimentos em Argissolo Vermelho-Amarelo em floresta e milho cultivado com adubação mineral e orgânica, Leite et al. (2003) verificaram que o C-HUM constituiu cerca de 50 a $60 \%$ do COT em todos os sistemas de produção. Ao estudarem a quantificação de $\mathrm{C}$ das substâncias húmicas em diferentes sistemas de uso do solo e épocas de avaliação, Loss et al. (2010) constataram que o C-HUM representava de 65 a $71 \%(0,00-0,05 \mathrm{~m})$ e 63 a $78 \%(0,05-0,10 \mathrm{~m})$ do COT. Os autores reportaram ainda correlações significativas do C-HUM com SB, T e DMP dos agregados (Loss et al., 2009).

\section{Análise de Componentes Principais (ACP)}

A análise de componentes principais foi realizada a partir das interpretações feitas na distribuição dos atributos químicos e físicos do solo das áreas impactadas e da área de referência (Figura 3). No gráfico ACP, evidencia-se a separação em três grupos, explicados em 70,26\% em dois componentes (F1 52,72 \% e F2 17,54\%). Ao avaliar os atributos químicos e físicos de Argissolo Vermelho-Amarelo em sistema integrado de produção agroecológica, Loss et al. (2009), com emprego de ACP, realizada sobre o conjunto de dados químicos e físicos dos solos, verificaram que os dois primeiros eixos explicaram $72,97 \%$ da variabilidade total dos dados, dos quais $49,54 \%$ no eixo F1 e 23,43 \% no eixo F2, corroborando com os encontrados neste estudo.

Houve separação da área de referência, sem impacto (A1), das áreas impactadas, e o principal atributo correlacionado com essa área foi a Ds nas duas profundidades avaliadas. As áreas A4 e A5 foram similares e se separaram das demais áreas. Essa similaridade está associada aos elevados teores de areia e densidade de partículas $(\mathrm{Dp})$, verificados nessas áreas onde ocorreu o transbordamento do rio. $\mathrm{Na}$ área A3, foram observadas as maiores correlações dos teores de COT e seus compartimentos químicos e físicos com os teores de argila e com o DMP, que evidenciou que essa área já apresenta certa estabilização nos compartimentos de C. A área A2 foi a que mais demonstrou correlação com a área A1, o que significa que essa área possui atributos químicos e físicos semelhantes à área onde não ocorreu impacto.

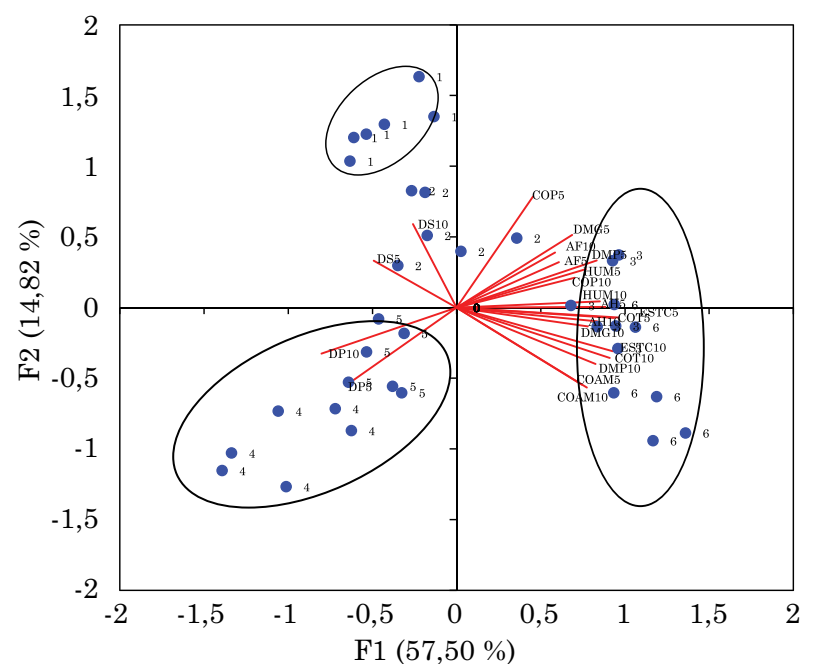

Figura 3. Gráfico bi-plot obtido a partir da análise de componentes principais (ACP) na profundidade de 0,00-0,05 e 0,05-0,10 $\mathrm{m}$ das características químicas e físicas do solo, após impacto ambiental. 1: Sem impacto; 2: soterramento total e cultivo de aveia+ervilhaca; 3: transbordamento do rio e cultivo de milheto+girassol; 4: transbordamento do rio e grande deposição de areia e cultivo de aveia-preta; 5: transbordamento do rio, o que ocasionou grande deposição de areia e sem cultivo; e 6: transbordamento do rio em menor escala e sem cultivo. AR: areia; ARG: argila; SIL: silte; DS: densidade do solo; DP: densidade da partícula; DMP: diamnetro médio ponderado; DMG: diâmetro médio geométrico; COT: carbono orgânico total; COP: carbono orgânico particulado; COAM: carbono orgânico mineral; AF: ácido fúlvico; $\mathrm{AH}$ : ácido húmico; e HUM: humina.

\section{CONCLUSÕES}

As áreas se diferenciaram quanto aos atributos avaliados, sendo os químicos dependentes dos físicos, principalmente da textura. Os menores valores de carbono e suas frações químicas e físicas foram observados nas áreas impactadas pelo transbordamento do rio e grande deposição de areia.

As áreas impactadas apresentaram elevados níveis de fertilidade em razão das constantes adubações químicas realizadas nas áreas de estudo, com valores de P e K classificados como muito alto.

O fracionamento químico e o físico da matéria orgânica do solo foram ferramentas úteis para identificar a heterogeneidade e herança do material transportado durante os eventos de transporte e deposição de sedimentos em 
áreas impactadas, apresentando diferenças significativas mesmo em curto prazo.

A análise de componentes principais estratificou as áreas estudadas e correlacionou a influência do impacto ambiental com os atributos químicos e físicos das áreas estudadas. As maiores diferenças nos atributos estudados foram verificadas em detrimento da diferença de textura encontrada nas áreas e do menor grau à cobertura utilizada.

\section{AGRADECIMENTOS}

Ao CNPq, à FAPERJ, UFRRJ/CPGA-CS, Embrapa Agrobiologia e à Sra. Margarete Tiba Ferreira, agricultora, pelo apoio.

\section{REFERÊNCIAS}

Amado TJC. Disponibilidade de nitrogênio para o milho em sistemas de cultura e preparo do solo [tese]. Porto Alegre: Universidade Federal do Rio Grande do Sul; 1997.

Barreto AC, Freire MBGS, Nacif PGS, Araújo QR, Freire FJ, Inácio ESB. Fracionamento químico e físico do carbono orgânico total em um solo de mata submetido a diferentes usos. R Bras Ci Solo. 2008;32:1471-8.

Bayer C, Mielniczuk J, Martin-Neto L, Pavinato A. Armazenamento de carbono em frações lábeis da matéria orgânica de um Latossolo Vermelho sob plantio direto. Pesq Agropec Bras. 2004;39:677-83.

Benites VM, Madari B, Machado PLOA. Extração e fracionamento quantitativo de substâncias húmicas do solo: um procedimento simplificado de baixo custo. Rio de Janeiro: Embrapa Solos; 2003. (Comunicado técnico, 16).

Cambardella CA, Elliott ET. Particulate soil organic-matter changes across a grassland cultivation sequence. Soil Sci Soc Am J. 1992;56:777-83.

Cardozo SV, Pereira MG, Ravelli A, Loss A. Caracterização de propriedades edáficas em áreas sob manejo orgânico e natural na região serrana do Estado do Rio de Janeiro. Semina Ci Agrár. 2008;29:517-30.

Carter MR. Organic matter and sustainability. In: Rees RM, Ball BC, Campbell CD, Watson CA, editors. Sustainable management of soil organic matter. New York: CABI Publishing; 2001. p.9-22.

Christensen BT. Organic matter in soil: structure, function and turnover. Tjele: 2000. (DIAS Report. Plant Production, 30).

Conceição PC, Amado TJC, Mielniczuk J, Spagnollo E. Qualidade do solo em sistemas de manejo avaliada pela dinâmica da matéria orgânica e atributos relacionados. R Bras Ci Solo. 2005;29:777-88.

Empresa Brasileira de Pesquisa Agropecuária - Embrapa. Centro Nacional de Pesquisa Agropecuária de Solos. Manual de métodos de análise de solo. $2^{\text {a }}$. ed. Rio de Janeiro: 1997.
Ferreira MM. Caracterização física do solo. In: Jong van Lier Q, editor. Física do solo. Viçosa, MG: Sociedade Brasileira de Ciência do Solo; 2010. p.1-28.

Gregorich EG, Carter MR, Angers DA, Monreal CM, Ellert BH. Towards a minimum data set to assess soil organic matter quality in agricultural soils. Can J Soil Sci. 1994;74:367-75.

Leite LFC, Mendonça ES, Machado PLOA, Matos ES. Total $\mathrm{C}$ and $\mathrm{N}$ storage and organic $\mathrm{C}$ pools of a Red-Yellow Podzolic under conventional and no tillage at the Atlantic Forest Zone, Southeastern Brazil. Aust J Soil Res. 2003;41:717-30.

Loss A, Pereira MG, Anjos LHC, Giacomo SG, Perin A. Agregação, carbono e nitrogênio em agregados do solo sob plantio direto com integração lavoura-pecuária. Pesq Agropec Bras. 2011;46:565-79.

Loss A, Pereira MG, Schultz N, Anjos LHC, Silva EMR. Quantificação do carbono das substâncias húmicas em diferentes sistemas de uso do solo e épocas de avaliação. Bragantia. 2010;69:913-22.

Loss A, Pereira MG, Schultz N, Anjos LHC, Silva EMR. Atributos químicos e físicos de um Argissolo Vermelho-Amarelo em sistema integrado de produção agroecológica. Pesq Agropec Bras. 2009;44:1-10.

Melloni R, Melloni EGP, Vieira LV. Uso da terra e a qualidade microbiana de agregados de um Latossolo Vermelho-Amarelo. $\mathrm{R}$ Bras Ci Solo. 2013;37:1678-88.

Mielniczuk J. Matéria orgânica e sustentabilidade de sistemas agrícolas. In: Santos GA, Silva LS, Canellas LP, Camargo FAO, editores. Fundamentos da matéria orgânica do solo: ecossistemas tropicais e subtropicais. $2^{\text {a }}$. ed. Porto Alegre: Metrópole; 2008. p.1-5.

Pinheiro EFM, Pereira MG, Anjos LHC. Fracionamento densimétrico da matéria orgânica do solo sob diferentes sistemas de manejo e cobertura vegetal em Paty do Alferes (RJ). R Bras Ci Solo. 2004;28:731-7.

Portz A, Resende AS, Teixeira AJ, Abboud SCA, Martins CAC, Carvalho CAB, Lima E, Zonta E, Pereira JBA, Balieiro FC, Almeida JCC, Souza JF, Guerra JGM, Macedo JR, Souza JN, Freire LR, Vasconcelos MAS, Leal MAA, Ferreira MBC, Manhães M, Gouve RF, Busquet RNB, Bhering SB. Recomendações de adubos, corretivos e de manejo da matéria orgânica para as principais culturas do Estado do Rio de Janeiro. In: Manual de calagem e adubação do Estado do Rio de Janeiro. Seropédica: Universidade Federal Rural do Rio de Janeiro; 2013. v.1.

Reinert DJ, Reichert J. Propriedades físicas de solos em sistema plantio direto irrigado. In: Carlesso R, Petry M, Rosa G, Ceretta CA, editores. Irrigação por aspersão no Rio Grande do Sul. Santa Maria: 2001. p.114-31.

Santos DC, Farias MC, Lima CLR, Kunde RK, Pillon CN, Flores CA. Fracionamento químico e físico da matéria orgânica de um Argissolo Vermelho sob diferentes sistemas de uso. Ci Rural. 2013b;43:838-44.

Santos HG, Jacomine PKT, Anjos LHC, Oliveira VA, Lumbreras JF, Coelho MR, Almeida JA, Cunha TJF, Oliveira JB. Sistema brasileiro de classificação de solos. $3^{\text {a }}$. ed. Brasília, DF: Embrapa; 2013a.

Secretaria de Estado de Agricultura e Pecuária - SEAPEC-RJ. 2011. [Acessado em: Jun. 2012] Disponível em: http://www. rj.gov.br. 
Silva FAS, Azevedo CAV. Versão do programa computacional Assistat para o sistema operacional Windows. R Bras Prod Agron. $2002 ; 4: 71-8$.

Sisti CPJ, Santos HP, Kohhann R, Alves BJR, Urquiaga S, Boddey MB. Change in carbon and nitrogen stocks in soil under 13 years of conventional or zero tillage in southern Brazil. Soil Till Res. 2004;76:39-58.

Souza WJO, Melo WJ. Matéria orgânica em um Latossolo submetido a diferentes sistemas de produção. R Bras Ci Solo. 2003;27:1113-22.

Stevenson FJ. Humus chemistry: genesis, composition, reactions. New York: John Wiley; 1994.
Swift RS. Organic matter characterization. In: Sparks DL, Page AL, Helmke PA, Loeppert RH, Soltanpour PN, Tabatabai MA, Johnston CT, Sumner ME, editors. Methods of soil analysis: chemical methods. Madison: Soil Science Society of America/American Society of Agronomy; 1996. p.1011-20.

Turetta APD. Alterações edáficas em função do manejo agrícola de oleráceas em Latossolo Vermelho no bioma Mata Atlântica - Paty do Alferes, RJ [dissertação]. Seropédica: Universidade Federal Rural do Rio de Janeiro; 2000.

Yeomans JC, Bremner JM. A rapid and precise method for routine determination of organic carbon in soil. Commun Soil Sci Plant Anal. 1988;19:1467-76. 